DOI: $10.20396 /$ cel.v61i0.8654429

\title{
AGRUPAMENTOS FONÉTICOS DA VOGAL MÉDIA ANTERIOR /E/ EM POSIÇÃO PRETÔNICA NO ATLAS LINGUÍSTICO DE RONDÔNIA (ALIRO)
}

\author{
ABDELHAK RAZKY ${ }^{1}$ \\ IARA MARIA TELES ${ }^{2}$ \\ DIEGO COIMBRA ${ }^{3}$
}

\begin{abstract}
RESUMO: Este estudo trata da análise e cartografia da variação da vogal média pretônica /e/ a partir do corpus do Projeto Atlas Linguístico de Rondônia - ALiRO. O trabalho segue a orientação teórico-metodológica da Dialetologia Pluridimensional e Relacional (RADTKE; THUN, 1996), da Geossociolinguística (RAZKY, 1998; 2004; 2010), da Sociolinguística Quantitativa (GUY; ZILLER, 2007) e da noção de agrupamento (RAZKY, 2013; RAZKY; GUEDES, 2015; RAZKY; COIMBRA; COSTA, 2017). Foram analisados dados de 62colaboradores distribuídos entre os 16 pontos de inquérito que compõem a rede de pontos do ALiRO, os quais foram estratificados conforme os grupos de fatores considerados no referido projeto, quais sejam: faixa etária (dois informantes de 18 a 30 anos e dois de 50 a 65 anos); sexo (dois homens e duas mulheres); e localidade (microrregiões e municípios). Em Porto Velho, capital, tem-se 8 colaboradores estratificados em sexo (quatro homens e quatro mulheres), faixa etária (quatro informantes de 18 a 30 anos e quatro informantes de 50 a 65 anos) e escolaridade (quatro até o ensino médio e quatro com nível superior). Foram investigadas três realizações da vogal média pretônica anterior /e/, a saber: abaixamento, alçamento e manutenção. Os resultados mostram que o fator diageracional influencia o abaixamento e a manutenção da vogal /e/, uma vez que o abaixamento foi mais recorrente na fala dos informantes mais velhos, ao passo que a manutenção predominou na fala dos mais jovens. O estudo demonstra, ainda, que há quatro tipos de agrupamentos fonéticos no território rondoniense, os quais corroboram com a noção de agrupamento adotada nesta pesquisa.

Palavras-chave: agrupamentos fonéticos; vogais média pretônica/e/, geossociolinguística. ALiRO.
\end{abstract}

ABSTRACT: This paper deals with the analysis and cartography of the variation of the pretonic front vowel /e/ from the corpus of Linguistic Atlas of Rondônia - ALiRO. This work follows the theoreticalmethodological orientation of the Pluridimensional and Relational Dialectology (RADTKE, THUN, 1996), Geosociolinguistics (RAZKY, 1998, 2004, 2010), Quantitative Sociolinguistic (GUY, ZILLER, 2007), and the grouping notion (RAZKY, 2013; RAZKY; GUEDES, 2015; RAZKY; COIMBRA; COSTA, 2017). Data from 62 informants distributed among 16 geographical points that compose ALiRO's network were stratified according to the variables considered in ALiRO project, namely: age group (two informants aged 18 to 30 and two aged 50 to 65 years); sex (two men and two women); and

${ }^{1}$ Universidade Federal do Pará (UFPA), Belém, PA, Brasil. arazky@gmail.com, https://orcid. org/0000-0001-9250-8917

${ }^{2}$ Universidade Federal de Rondônia (UNIR), Porto Velho, RO, Brasil. itelles18@gmail.com, https://orcid.org/0000-0001-5610-0666

${ }^{3}$ Universidade Federal do Pará (UFPA), Belém, PA, Brasil. diegocoimbrast@gmail.com, https:// orcid.org/0000-0002-0980-7922 
locality (microregions and cities). In Porto Velho, capital, 8 informants were stratified according to sex (four men and four women), age group (four informants aged 18 to 30 and four informants aged 50 to 65 ) and schooling (four with high school degrees and four with university degrees). Three realizations of the pretonic front vowel /e/ were investigated, namely: lowering, raising and maintenance. The results show that the diagenerational factor influences the lowering and maintenance of the vowel /e/, since the lowering was recurrent in the speech of the older informants, while maintenance predominated in the speech of younger ones. The study also shows that there are four types of phonetic geographical groupings in Rondônia state, which corroborate the notion of grouping adopted in this research.

Keywords: phonetic grouping; pretonic mid front vowel /e/; geossociolinguistics; ALiRO.

\section{INTRODUÇÃO}

Este estudo visa descrever o comportamento da vogal média /e/ em posição pretônica a partir do banco de dados do Projeto Atlas Linguístico de RondôniaALiRO, centrando sua análise na distribuição geográfica, bem como na influência dos fatores sociais controlados. Buscou-se, ainda, realizar uma macroanálise da vogal em escopo - não levando em consideração o efeito dos fatores fonológicos internos -, a fim de priorizar a descrição do contínuo variacional da vogal média pretônica /e/. O principal objetivo é a apresentação de cartas linguísticas acompanhadas de uma análise geossocial integrada ao conceito de agrupamento (RAZKY, 2013; RAZKY; GUEDES, 2015; RAZKY; COIMBRA; COSTA, 2017). As frequências obtidas para cada uma das variantes encontradas (abaixamento, alçamento e manutenção $)^{4}$ são dispostas em cartas fonéticas.

Diante disso, analisou-se a variação de /e/ pretônico seguindo as orientações metodológicas da Geossociolinguística (RAZKY, 1998; 2004; 2010), buscando documentar os aspectos fonéticos característicos do português falado no estado de Rondônia. A proposta de análise é inédita pelo fato de ser o primeiro trabalho a usar o banco de dados do ALiRO e o primeiro a mapear a vogal média /e/ em um projeto de atlas estadual em curso. Ademais, este estudo fornece resultados acerca das vogais médias pretônicas no português falado no estado de Rondônia, contribuindo para ampliação do conhecimento acerca dessa temática tanto do ponto de vista espacial quanto social.

Por fim, para melhor situar o trabalho, procurou-se, ainda, apresentar, brevemente, os rumos da Dialetologia moderna, o impacto da perspectiva pluridimensional e/ou geossociolinguístico sobre os estudos dialetais, além da seleção de uma literatura pertinente sobre as vogais médias em posição pretônica do português falado na região Norte do Brasil.

\section{O ESTADO DE ARTE DA LITERATURA EM ESCOPO}

\subsection{Horizontes recentes da dialetologia}

A Dialetologia tradicional - ou horizontal - tinha como principal objetivo demonstrar a variedade fonético-fonológica, semântico-lexical e/ou morfossintática

\footnotetext{
${ }^{4}$ Considera-se, neste estudo, manutenção como sendo a forma invariável da vogal média anterior /e/ em posição pretônica.
} 
de determinada área geográfica, despreocupando-se, na maior parte de sua produção científica, com aspectos diastráticos. No final da segunda metade do século XIX, Gilliéron e Edmont elaboraram o Atlas Linguistique de la France$A L F$, sendo esse considerado o atlas linguístico que iniciou a tradição dialetológica na Europa ${ }^{5}$ por sua sistematicidade na recolha e tratamento de dados. No entanto, não houve controle de estratificação dos informantes (sexo, faixa etária, profissão, escolaridade etc.), embora se saiba que havia preferência por informantes mais velhos, menos escolarizados e que residiam na zona rural da França por serem considerados portadores de um dialeto mais "puro"6 (CARDOSO, 2010).

A partir de 1960, "os estudos geolinguísticos tomaram uma nova orientação, pois passaram a inserir alguns pressupostos metodológicos da Sociolinguística, agregando ao fator diatópico variáveis sociais" (ISQUERDO; ROMANO, 2012, p. 894). A Dialetologia moderna constitui um rompimento com a Dialetologia horizontal, pois a primeira passa a analisar a variável geográfica concomitantemente com aspectos referentes à dimensão social em que o falante se insere.

Essa nova linha de análise da Dialetologia tomou forma com a Dialetologia Pluridimensional e Relacional (RADTKE; THUN, 1996), a qual sistematiza os aspectos do eixo horizontal (Dialetologia) com os aspectos do eixo vertical e diagonal (Sociolinguística). O produto desse intercruzamento de eixos é uma gama de possibilidades de aplicação metodológica que visam descrever e explicar, com maior precisão, fenômenos de diferentes naturezas linguísticas.

No Brasil, a elaboração, em 1996, do Projeto Atlas Linguístico do Brasil - ALiB contribuiu para o que Mota e Cardoso (2006) denominaram de quarta fase dos estudos dialetais. O Projeto ALiB constituiu uma metodologia rígida de recolha de dados, a qual exerceu influência sobre grande parte dos estudos dialetais que o sucederam. A exemplo disso, têm-se os atlas regionais, bem como teses, dissertações e artigos que seguiram a mesma linha de investigação. A metodologia do ALiB, que foi aplicada em diferentes projetos de atlas linguísticos, permite que sejam elaborados estudos comparativos entre esses atlas, a fim de se estabelecer características interdialetais entre diferentes espaços geográficos.

Ademais, a forma de cartografar a variação linguística ganhou uma dimensão eletrônica com a publicação, em 2004, do primeiro atlas digital do Brasil, o Atlas Linguístico Sonoro do Pará - ALiSPA, o qual influenciou a maneira de organizar, armazenar e disponibilizar dados dialetais que deram forma à elaboração da maquete do GeoLin 7 , ainda em teste, e do programa SGVCLIN (ROMANO et al., 2014), já utilizado por dialetólogos.

${ }^{5}$ Embora a primeira tentativa de elaboração de um atlas linguístico seja atribuída a Wenker, a fragilidade metodológica do Atlas Linguístico da Alemanha, publicado em 1881, fez com que fosse considerado um estudo de pouca confiabilidade.

${ }^{6}$ Acreditava-se que os falantes que residiam na zona rural possuíam um dialeto em sua forma mais pura (ou mais próxima da forma original) devido ao fato de seu dialeto não ter sido "corrompido" pelos falares urbanos. Ademais, evitavam-se informantes com alto grau de escolaridade, pois assumiase que esses informantes possuíam seu dialeto modificado pela escrita literária.

${ }^{7}$ Razky e Rodrigues (2019, no prelo). 
A partir dessa nova acepção da Dialetologia brasileira, a elaboração de isoglossas vem mostrando suas limitações devido às grandes mudanças societais no Brasil que culminaram em grandes movimentos populacionais, uma grande concorrência no setor de transporte público e transporte aéreo, além da descentralização de oportunidades de trabalho e empreendimento.

Essa nova dinâmica migratória e mobilidade de recursos humanos provocaram mudanças importantes no âmbito da competência variacional dos falantes, pois influenciaram no desenvolvimento de uma competência bidialetal e pluridialetal dos falantes da primeira geração dos imigrantes, a qual influiu sobre a competência dialetal das gerações subsequentes. O resultado disso é a presença de uma significativa variabilidade linguística no mesmo espaço geográfico em termos de agrupamentos dialetais (RAZKY, 2010).

Havia, portanto, uma competência geolinguística local e uma competência sociolinguística com estratificações geográficas e sociais homogêneas que permitiam traçar isoglossas significativas para a Dialetologia tradicional. Com a dinamicidade dos movimentos populacionais, essa competência linguística monodimensional cedeu espaço para uma competência geossociolinguística complexa que reflete a complexidade de cada falante e de cada comunidade linguística. Por isso, a noção de agrupamento, seja ele lexical ou fonético, torna-se uma resposta viável para dar conta da complexidade variacional.

O conceito de agrupamento lexical vem acompanhando essa mudança em curso do léxico que, por sua vez, é fruto de uma mobilidade geográfica dos falantes e do acesso ao universo lexical do outro, através dos meios de comunicação. Além disso, o fluxo de interações verbais, fruto de redes de comunicações complexas, vem quebrando o paradigma de isolexias ou, pelo menos, o colocando dentro de um conceito do contínuo linguístico bem conhecido dos estudos sociolinguísticos (RAZKY, 2013, p. 263).

A noção de agrupamento lexical, que se aplica também à variação fonética, deu aos estudos geossociolinguísticos uma compreensão maior acerca dos fenômenos linguísticos, uma vez que "le concept de regroupement lexical répond ainsi à cette dynamique linguistique que d'autres chercheurs ont pu dégager dans le cadre d'une dialectologie pluridimensionnelle" (RAZKY; GUEDES, 2015, p. 161). A noção de agrupamento está, aos poucos, substituindo o conceito de isoglossas, buscando preencher a lacuna teórico-metodológica no que concerne às mudanças sociais no Brasil que refletem diretamente em configurações diatópicas complexas e que necessitam de olhar exploratório quanto à interpretação dos dados dialetais.

A utilização de agrupamentos permite delinear uma tipologia em macroagrupamentos, microagrupamentos, nanoagrupamentos e supraagrupamentos. Macroagrupamento, dentro de um atlas estadual, diz respeito a uma variante linguística presente em um conjunto de localidades pertencentes a mais de uma microrregião do estado; microagrupamento se refere à ocorrência de

8 "o conceito de agrupamento lexical responde assim a essa dinâmica linguística que outros pesquisadores conseguiram identificar no contexto de uma dialetologia pluridimensional" (tradução nossa). 
uma variante lexical ou fonética em um conjunto de localidades dentro de uma microrregião; um nanoagrupamento é a presença de uma variante em poucas localidades pertencentes a uma microrregião; e o supra-agrupamento, por sua vez, é uma manipulaçãodo conjunto das variantes de uma localidade, selecionando apenas a variante mais produtiva em cada uma delas.

Essa tipologia é capaz de responder à complexidade da variação em dado espaço geográfico. Quando se aplica uma metodologia geossociolinguística, em que há uma estratificação social, obtêm-se resultados mais complexos do que na aplicação de metodologias da Dialetologia tradicional. Assim, ao invés de traçar isolexias ou isofonias, desenham-se linhas que se intercruzam para mostrar contornos fonéticos ou lexicais com configurações diatópicas ou diastráticas mais complexas.

\subsection{Uma amostra de estudos dialetais sobre as vogais pretônicas}

O comportamento da vogal média pretônica tem sido objeto de estudo de vários especialistas. Podem-se citar os trabalhos de Nascentes (1953), Silva Neto (1963), Câmara Jr. (1977), Bisol (1981) e Callou e Leite (1991) como sendo estudos clássicos acerca dessa temática.

Segundo Aragão (2009, p. 2250), o motivo pelo qual as vogais pretônicas têm despertado interesse de estudiosos da área é devido ao "fato de que as pretônicas são consideradas uma das marcas mais importantes para a divisão dialetal do Brasil. Nascentes usou este critério para a separação entre os falares do Norte e os do Sul do país"". Embora Nascentes (1953) tenha levantado que a diatopia é um aspecto importante para a realização da vogal pretônica, outros estudos demonstram que elementos estruturais internos da língua influenciam no alçamento ou abaixamento dessa vogal. Questionamentos sobre se são os aspectos linguísticos ou extralinguísticos que determinam a forma como a vogal média em posição pretônica será realizada ainda são retomados, buscando maior precisão no quadro teórico acerca dessas vogais.

Embora se possam listar exaustivamente os estudos de caráter dialetal acerca das vogais médias pretônicas, destacam-se, nesta pesquisa, alguns estudos na Região Norte do Brasil.

Razky, Lima e Oliveira (2012) verificaram o comportamento das vogais médias em posição pretônica em 10 localidades do Atlas Linguístico Sonoro do Pará - ALiSPA. Os autores constataram a predominância da realização fechada dessas vogais. No entanto, destacam que, nas localidades que sofreram fluxo migratório de nordestinos mais intensificado, houve maior frequência de vogais abertas. As variáveis sociais não foram determinantes na escolha da altura das vogais pretônicas.

${ }^{9}$ Nascentes (1953) propôs a divisão dos dialetos brasileiros em Norte e Sul. O autor subdividiu esses dois grupos em subfalares: subfalar amazônico, nordestino, baiano, fluminense, mineiro e sulista. Para ele, a realização das vogais pretônicas de forma mais aberta caracterizaria o dialeto do Norte, ao passo que a realização mais fechada dessa vogal caracterizaria o dialeto do Sul. 
Tomando como base as cartas fonéticas do Atlas Linguístico do Amazonas ALAM e do Atlas Linguístico Sonoro do Pará - ALiSPA, Brandão e Cruz (2005) levantaram resultados percentuais, a fim de comparar os dados sobre as vogais médias pretônicas em ambos os atlas. Para a vogal média anterior, os resultados mostraram que, no Amazonas, há maior frequência de realização de vogais fechadas, enquanto que, no Pará, há predominância de vogais abertas. O alçamento ocorre com maior incidência em ambos os atlas quando a vogal pretônica inicia o vocábulo. Para a vogal média posterior, a tendência é de realização fechada em ambos os atlas. O alçamento dessa vogal ocorre majoritariamente em contexto de hiato.

Dias (2012), ao estudar as vogais médias em posição pretônica nas capitais do ALiB/Norte, identificou maior número de ocorrência de manutenção tanto da vogal anterior /e/ quanto da vogal posterior /o/. O autor propôs uma divisão entre /e/ e /o/, embora os fenômenos que ocorrem em ambas as vogais fossem os mesmos (abaixamento, alçamento e manutenção). Essa divisão se justifica pelo fato de que os fatores linguísticos que favorecem esses fenômenos não são os mesmos para /e/ e /o//. Dias (2012) afirma que, quando a vogal tônica é alta, há maior tendência de ocorrer alçamento na pretônica, bem como a vogal tônica baixa influi no abaixamento da pretônica. A variação diassexual apontou que os homens utilizam mais o alçamento da pretônica, enquanto as mulheres abaixam ou mantém a vogal. A variação diageracional mostrou que os mais velhos têm mais propensão a alçar a vogal pretônica, enquanto os mais novos a mantêm. Quanto à escolaridade, os mais escolarizados tendem a manter a vogal, ao passo que, entre os menos escolarizados, a tendência de alçamento é maior. No que concerne ao fator diatópico, o alçamento se concentrou na parte setentrional da região Norte (Belém e Macapá), enquanto que o abaixamento da pretônica ocorreu predominantemente na parte meridional nortista (Rio Branco, Porto Velho e Manaus).

O que se nota, a partir dos estudos dialetais levantados, é que, na Região Norte, há uma tendência de realização fechada das vogais médias /e/ e /o/ em posição pretônica, seguida do alçamento em [i] e [u] dessas vogais. Esse resultado demonstra que houve uma mudança linguística ao comparar esses resultados com as conclusões de Nascentes (1953), o qual assumia que as vogais abertas $/ \varepsilon / \mathrm{e} / \mathrm{J} /$ seriam predominantes no grupo Norte, onde a região Norte estaria agrupada como subfalar amazônico.

\section{METODOLOGIA}

O presente trabalho segue uma orientação geossociolinguística. Baseiase em uma investigação in loco elaborada pela equipe do projeto $\mathrm{ALiRO}^{10}$ a partir de uma rede de pontos, uma amostra de informantes estratificados e um questionário fonético-fonológico. Os dados organizados em um banco de dados foram submetidos a uma análise geossocial conforme os aspectos metodológicos em seguida apresentados.

${ }^{10}$ O Projeto ALiRO é coordenado pela Prof. ${ }^{a}$ Iara Maria Telles, tendo como consultor o Prof. Abdelhak Razky (UFPA/UnB/CNPq) e a Prof. ${ }^{a}$ Vanderci Aguilera (UEL/CNPq) 
O corpus do ALiRO apresenta 62 informantes no total, dos quais 54 residem na zona rural do estado de Rondônia, os quais estão estratificados ${ }^{11}$ em sexo (dois homens e duas mulheres) e faixa etária (dois informantes de 18 a 30 anos e dois informantes de 50 a 65 anos). No caso de Porto Velho, capital, tem-se 8 informantes estratificados em sexo (quatro homens e quatro mulheres), faixa etária (quatro informantes de 18 a 30 anos e quatro informantes de 50 a 65 anos) e escolaridade $^{12}$ (quatro informantes com ensino fundamental e quatro informantes com ensino superior).

A rede de pontos do ALiRO apresenta 16 pontos de inquérito, como mostra o Quadro 01.

Quadro 01. Localidades investigadas

\begin{tabular}{|c|c|c|}
\hline MICRORREGIÕES $^{10}$ & NUMERAÇ̃̃o $^{*}$ & MUNIĆ́PIO \\
\hline \multirow{4}{*}{ Norte } & 01 & Porto Velho \\
\cline { 2 - 3 } & 02 & Candeias \\
\cline { 2 - 3 } & 03 & São Carlos \\
\cline { 2 - 3 } & 04 & Calama \\
\hline \multirow{4}{*}{$\begin{array}{c}\text { Vale do Guaporé- } \\
\text { Mamoré }\end{array}$} & 05 & Guajará-Mirim \\
\cline { 2 - 3 } & 06 & Costa Marques \\
\cline { 2 - 3 } & 08 & Seringueiras \\
\cline { 2 - 3 } & 09 & Porto Murtinho \\
\hline
\end{tabular}

${ }^{11}$ As estratificações dos informantes elencadas para a recolha de dados (faixa etária, sexo e escolaridade) seguem as variáveis definidas no Comitê Nacional do ALiB (2001), as quais buscam atender às possibilidades de uma melhor comparação entre usos de diferentes faixas etárias e, também, propiciar a análise da variação e da mudança linguística.

${ }^{12}$ Esse fator não foi controlado nesta pesquisa.

${ }^{13}$ Denominou-se Região Norte a microrregião de Porto Velho, constituída por dois municípios e dois distritos: Porto Velho (PI 01), Candeias (PI 02), São Carlos (PI 03) e Calama (PI 04). Denominouse Vale do Guaporé-Mamoré a microrregião de Guajará-Mirim, formada por cinco municípios: Guajará-Mirim (PI 05), Costa-Marques (PI 06), Seringueiras (PI 07), Porto Murtinho (PI 08) e Forte Príncipe da Beira (PI 09). Como a influência da colonização da Mesorregião do Leste Rondoniense foi, em sua maioria, da Região Sul do Brasil, denominou-se essa microrregião de Cone Sul, a qual comporta sete municípios: Alto Paraíso (PI 10), Ariquemes (PI 11), Jaru (PI 12), Ji-Paraná (PI 13), Pimenta Bueno (PI 14), Vilhena (PI 15) e Pimenteiras (PI 16). 


\begin{tabular}{|c|c|c|}
\hline \multirow{4}{*}{ Cone Sul } & 10 & Alto Paraíso \\
\cline { 2 - 3 } & 11 & Ariquemes \\
\cline { 2 - 3 } & 12 & Jaru \\
\cline { 2 - 3 } & 13 & Ji-Paraná \\
\cline { 2 - 3 } & 14 & Pimenta Bueno \\
\cline { 2 - 3 } & 15 & Vilhena \\
\cline { 2 - 3 } & 16 & Pimenteiras \\
\hline
\end{tabular}

Essas localidades estão distribuídas pelo território rondoniense em três microrregiões ${ }^{14}$, como mostra a Figura 01 .

Figura 01. Carta base do ALiRO

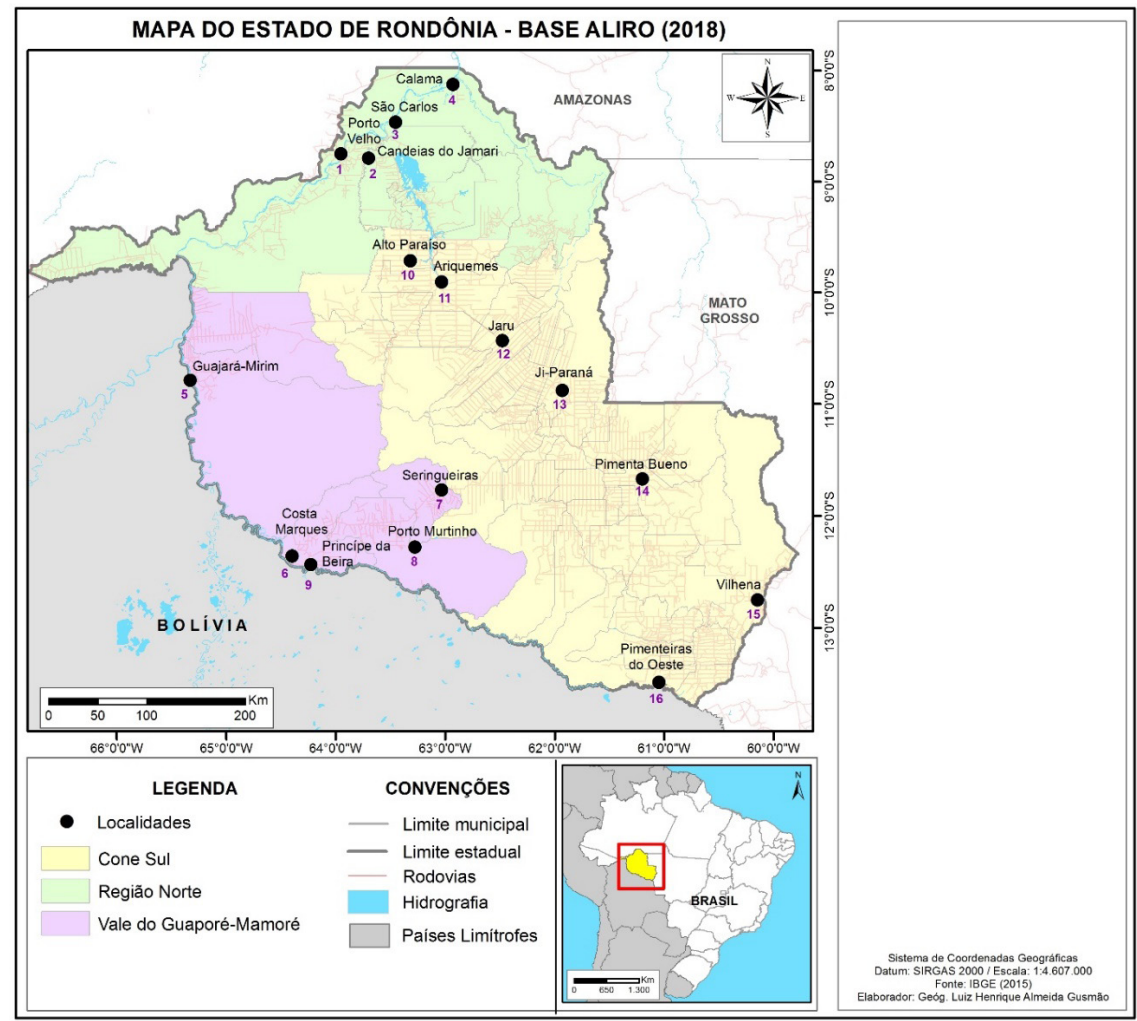

${ }^{14}$ A fim de obter uma amostra representativa do dialeto rondoniense, adotou-se a divisão em três regiões (Região Norte, Vale do Guaporé-Mamoré e Cone Sul), considerando três pontos: os rios Madeira e Guaporé-Mamoré; duas Mesorregiões: do Madeira-Mamoré e do Leste Rondoniense; e as influências recebidas de imigrantes na colonização de Rondônia, de acordo com Silva (1984). 
Quanto à recolha de dados do ALiRO, utilizou-se o Questionário FonéticoFonológico $(\mathrm{QFF})^{15}$, do qual se retiraram, para esta pesquisa, somente os itens que correspondem à vogal média /e/ em posição pretônica.

As respostas obtidas foram transcritas em planilhas estruturadas. A quantificação dos dados foi realizada com o auxílio do programa estatísticocomputacional GoldVarb X (SANKOFF; TAGLIAMONTE; SMITH, 2005) para, em seguida, organizá-los em tabelas. O mapeamento linguístico foi realizado com o programa de edição de imagens bidimensionais Adobe Photoshop CS6 Professional.

Para a análise dos resultados obtidos de cada variável ${ }^{16}$, dividiu-se da seguinte forma: a) dimensão diatópica, que foi subdividida em macroagrupamento, microagrupamento e nanoagrupamento; b) dimensão diastrática, que foi subdividida em sexo e faixa etária; e c) agrupamentos fonéticos.

\section{ANÁLISE DOS RESULTADOS}

A análise de dados apontou a presença de três variantes envolvendo a vogal média pretônica /e/: o alçamento (/e/ > [i]), o abaixamento $(/ \mathrm{e} />[\varepsilon])$ e a manutenção em [e].

Os resultados apontam a dimensão diatópica como fator determinante para o uso de cada variante, demonstrando uma concentração maior de cada uma dessas variantes em uma das microrregiões elencadas para este estudo. Ademais, dentre os fatores diastráticos, apenas o fator diageracional apresentou influência relativamente significativa, apontando o abaixamento de /e/ como mais recorrente na fala dos mais velhos. Observou-se, ainda, que os informantes mais jovens tendem a manter invariável a vogal /e/ em posição pretônica. Esses e outros aspectos estão descritos e analisados nas seções que seguem.

\subsection{Dimensão diatópica}

A análise da dimensão diatópica se subdivide em macroagrupamento, em que se verificou a tendência geral de/e/ pretônico em todo o estado; microagrupamento, em que se observou a configuração da variação dessa vogal nas microrregiões Vale do Guaporé-Mamoré, Cone Sul e região Norte; e nanoagrupamento, em que se observou o comportamento da vogal em análise em função de cada um dos 16 municípios do estado de Rondônia considerados neste estudo.

${ }^{15}$ O Questionário Fonético-Fonológico (COMITÊ NACIONAL DO PROJETO ALIB, 2001) apresenta 159 itens distribuídos, dos quais se utilizou, para a vogal média anterior pretônica /e/, (002) Terreno, (003) Prateleira, (004) Televisão, (006) Tesoura, (008) Travesseiro, (011) Elétrico, (027) Fervendo, (049) Elefante, (067) Estrada, (069) Desvio, (074) Seguro, (081) Emprego, (084) Escola, (106) Mentira, (110) Perdão, (123) Ferida, (126) Desmaio, (144) Perfume, (150) Perdida, (152) Perguntar e (158) Esquerdo.

${ }^{16}$ Nesta pesquisa, consideraram-se apenas os fatores extralinguísticos (localidades, faixa etária e sexo). 


\subsubsection{Macroagrupamento}

Em Rondônia, como mostra a Figura 02, há uma maior tendência de manutenção da vogal média anterior em posição pretônica (52\%). No entanto, o índice de alçamento dessa vogal constitui uma realização relativamente significativa no território rondoniense (36,1\%). Percebe-se também que, apesar da baixa frequência total $(11,9 \%)$, o abaixamento da vogal se fez presente em todas as localidades estudadas. Na seção 4.1.1.3, as ocorrências por localidade foram analisadas mais detalhadamente, podendo-se notar melhor a distribuição dessas variantes pelo território de Rondônia. Nesse contexto estadual, as três variantes constituem um macroagrupamento para cada variante (Ma1, Ma2 e Ma3: vide Figura 05) que cobre todo o espaço de Rondônia, com exceção da vogal baixa que não é registrada em 16-Pimenteiras. Esses macroagrupamentos exigem, no entanto, uma análise mais fina para melhor categorizar o impacto de cada variante do ponto de vista de sua frequência.

Figura 02. Vogal média anterior em posição pretônica (localidades)

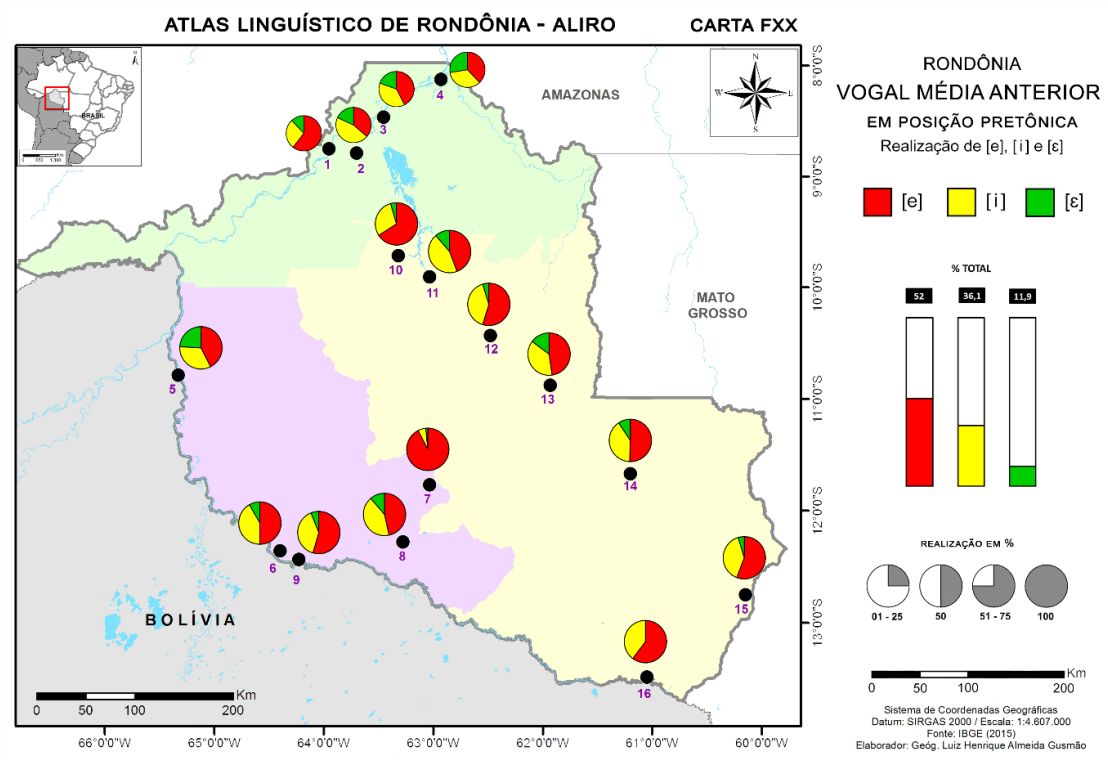

\subsubsection{Microagupamento}

Ao agrupar os valores de cada variante pelas três microrregiões, pode-se observar, de forma exploratória, duas frequências pequenas, mas pertinentes de alçamento no Cone Sul (17,9\%) e de abaixamento na região Norte (39,3\%). A Figura 03 mostra que, embora o abaixamento tenha obtido baixa frequência no território rondoniense, esse se concentrou na Região Norte, onde alcançou quase o dobro de frequência das demais microrregiões. 
Figura 03. Vogal média anterior em posição pretônica (microrregiões)

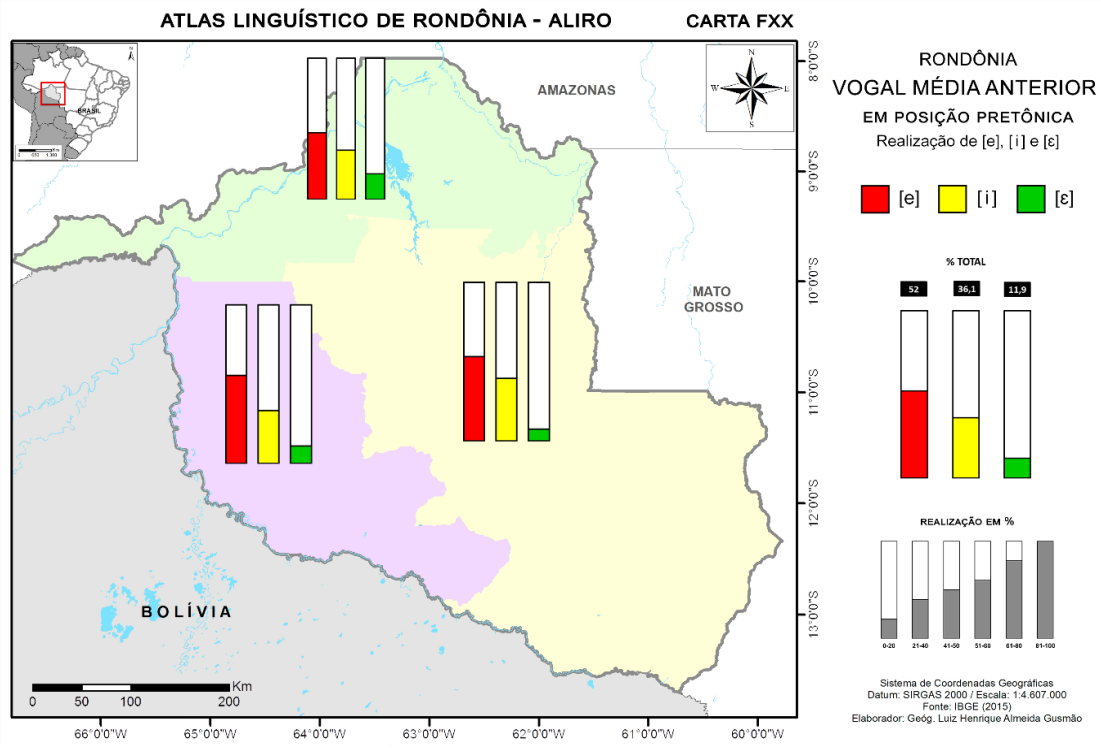

Ademais, a frequência de alçamento da vogal /e/ demonstrou ser estável ao comparar as três microrregiões, mas com uma pequena concentração na microrregião Cone Sul.

Como demonstra a Tabela 01, há uma preferência por se manter a vogal média anterior em posição pretônica em todas as microrregiões (entre 47,3\% e $55,5 \%$ ), a qual constitui o agrupamento Ma1 (Figura 05).

Tabela 01. Macrorregião

\begin{tabular}{|c|c|c|c|c|c|c|}
\hline & \multicolumn{2}{|c|}{ Abaixamento } & \multicolumn{2}{c|}{ Alçamento } & \multicolumn{2}{c|}{ Manutenção } \\
\hline Microrregião & Ocor./Total & $\mathbf{\%}$ & Ocor./Total & $\mathbf{\%}$ & Ocor.Total & $\%$ \\
\hline Norte & $77 / 429$ & $\mathbf{1 7 , 9}$ & $149 / 429$ & 34,7 & $203 / 429$ & 47,3 \\
\hline Guaporé-Mamoré & $43 / 391$ & 11 & $131 / 391$ & 33,5 & $217 / 391$ & $\mathbf{5 5 , 5}$ \\
\hline Cone Sul & $39 / 521$ & 7,5 & $205 / 521$ & $\mathbf{3 9 , 3}$ & $277 / 521$ & 53,2 \\
\hline Total & $\mathbf{1 5 9 / 1 3 4 1}$ & $\mathbf{1 1 , 9}$ & $\mathbf{4 8 5 / 1 3 4 1}$ & $\mathbf{3 6 , 2}$ & $\mathbf{6 9 7 / 1 3 4 1}$ & $\mathbf{5 2}$ \\
\hline
\end{tabular}

$\mathrm{O}$ alçamento, como mencionado, teve maior frequência na microrregião do Cone Sul (39,3\%), constituindo, portanto, um microagrupamento (Mil: vide Figura 06). O abaixamento, por sua vez, obteve maior frequência na região Norte $(17,9 \%)$, índice superior tanto à microrregião Guaporé-Mamoré $(11 \%)$ quanto ao 
Cone Sul (7,5\%). A Região Norte, então, apresenta um segundo microagrupamento (Mi2: vide Figura 06) da vogal baixa. Esse microagrupamento merece ser observado e mensurado, em outras pesquisas, no mesmo espaço e em relação com as localidades na fronteira com o estado do Amazonas.

\subsubsection{Nanoagrupamento e supra-agrupamento}

Como a presença das variantes fonéticas, no caso do ALiRO, precisa ser avaliada quantitativa e qualitativamente, observando sua realização em espaços maiores (macrorregional) e menores (microrregionais), há a necessidade de aumentar o foco nas próprias microrregiões para observar, nelas, a variação em cada localidade.

A Figura 02 evidencia uma distribuição significativa das variantes encontradas para a vogal média anterior. No entanto, pode-se destacar, como mencionado na seção anterior e como mostra o Gráfico 01, que os municípios que integram a Região Norte possuem maior concentração de abaixamento, a qual é majoritariamente encontrada em 04-Calama (27,6\%), 03-São Carlos (19,5\%) e 02-Candeias (18,2\%), bem como em 05-Guajará-Mirim (24,1\%), localidade que integra o Vale Guaporé-Mamoré.

Gráfico 01. Distribuição da variação do /e/ pretônico por localidade ${ }^{17}$

\section{VARIAÇÃO DE /E/ PRETÔNICO}

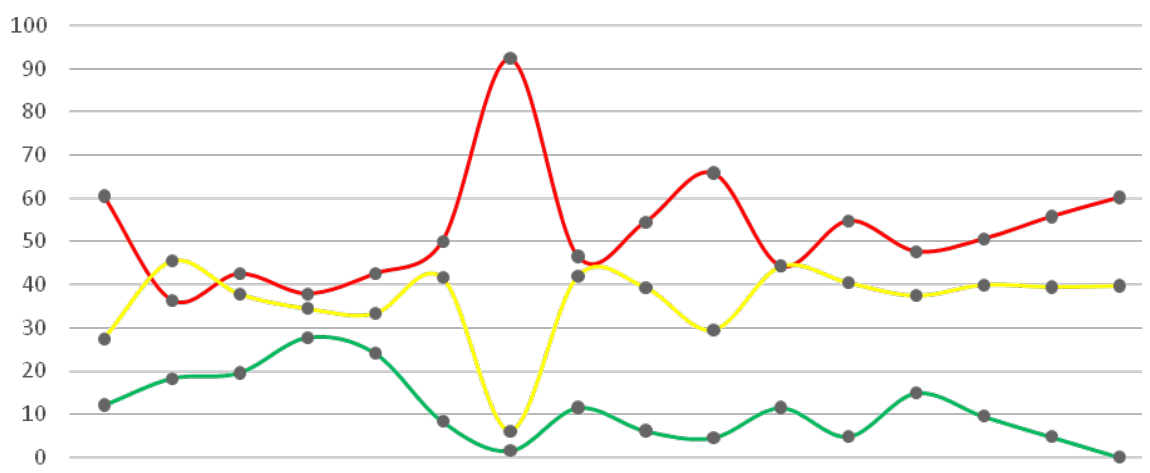

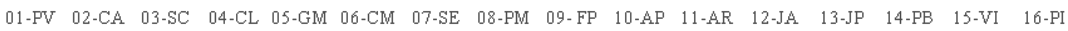

-Manutenção $\longrightarrow$ Alçamento $\rightarrow$ Abaixamento

A maior frequência de alçamento foi encontrada no município de 02-Candeias (45,5\%), embora os municípios de 11-Ariquemes (44,3\%), 08-Porto Murtinho (42\%), 06-Costa Marques (41,7\%), 12-Jaru (40,5\%) e 14-Pimenta Bueno (40\%) tenham obtido índices de frequência similares aos de 02-Candeias. A manutenção da vogal foi predominante em todos os municípios senão por 02-Candeias (36,4\%). É possível ver, a partir desses índices de frequência, que,

\footnotetext{
${ }^{17}$ A numeração que consta na legenda do gráfico segue a mesma numeração do Quadro 01 .
} 
nessas localidades da Região Norte, há um nanoagrupamento (Na1: vide Figura 06) do abaixamento do /e/ pretônico que se encontra dentro das camadas dos outros micro e macroagrupamentos presentes nessa região.

Percebe-se que uma análise em agrupamentos permite valorizar tanto os agrupamentos fonéticos maiores como os agrupamentos menores, a fim de fugir de uma tendência homogeneizante de isoglossas que traça uma cor num espaço geográfico, refletindo uma realidade mais impressionista do que realista. No sistema de cartografia em agrupamentos (RAZKY; GUEDES, 2015), que traça um conjunto de configurações espaciais, é possível acompanhar o complexo variacional de uma localidade ou grupo de localidade até um conjunto geral que compõe um atlas linguístico.

Do lado oposto de um nanoagrupamento, é possível fazer uma abstração da configuração variacional que caracteriza cada localidade estratificada socialmente para selecionar a variante predominante em cada uma delas. Essa operação, aplicada ao banco de dados da vogal média pretônica do projeto ALiRO, demonstra um agrupamento mais abstrato que pode ser comparado a uma isofonia tradicional. Nesse sentido, tem-se o processo de manutenção da vogal média que possivelmente aparecerá de forma representativa do estado do Amazonas. A partir disso, explica-se esse tipo de agrupamento como sendo um supra-agrupamento: um agrupamento que indica a frequência maior em cada localidade para traçar uma configuração mais homogênea, como se pode observar no Gráfico 01 e na Figura 02, os quais indicam a manutenção da vogal média como variante característica do estado de Rondônia

\subsection{Dimensão diastrática}

\subsubsection{Sexo}

O fator diassexual, como a Tabela 02 evidencia, não exerceu influência quanto à escolha das variantes da vogal média anterior, apresentando frequências muito similares tanto entre os informantes do sexo masculino quanto entre as informantes do sexo feminino.

Tabela 02. Sexo

\begin{tabular}{|c|c|c|c|c|c|c|}
\hline & \multicolumn{2}{|c|}{ Abaixamento } & \multicolumn{2}{c|}{ Alçamento } & \multicolumn{2}{c|}{ Manutenção } \\
\hline Sexo & Ocor./Total & $\mathbf{\%}$ & Ocor./Total & $\mathbf{\%}$ & Ocor./Total & \% \\
\hline Masculino & $83 / 670$ & 12,4 & $246 / 670$ & 36,7 & $341 / 670$ & 50,9 \\
\hline Feminino & $76 / 671$ & 11,3 & $239 / 671$ & 35,6 & $356 / 671$ & 53,1 \\
\hline Total & $\mathbf{1 5 9 / 1 3 4 1}$ & $\mathbf{1 1 , 9}$ & $\mathbf{4 8 5 / 1 3 4 1}$ & $\mathbf{3 6 , 2}$ & $\mathbf{6 9 7 / 1 3 4 1}$ & $\mathbf{5 2}$ \\
\hline
\end{tabular}




\subsubsection{Faixa etária}

Na Tabela 03, encontram-se as ocorrências e percentuais de ambas as faixas etárias. Pode-se notar que a segunda faixa etária tende a realizar com mais frequência o abaixamento $(15,9 \%)$ e o alçamento $(40,6 \%)$ da vogal pretônica anterior. Percebe-se, ainda, que a primeira faixa etária foi a que mais manteve a vogal invariável, atingindo $58,5 \%$ de frequência de manutenção.

Tabela 03. Faixa Etária

\begin{tabular}{|c|c|c|c|c|c|c|}
\hline & \multicolumn{2}{|c|}{ Abaixamento } & \multicolumn{2}{c|}{ Alçamento } & \multicolumn{2}{c|}{ Manutenção } \\
\hline Faixa etária & Ocor./Total & \% & Ocor./Total & \% & Ocor./Total & \% \\
\hline $1^{\text {a }}$ & $66 / 737$ & 9 & $240 / 737$ & 32,6 & $431 / 737$ & 58,5 \\
\hline $2^{\text {a }}$ & $93 / 604$ & 15,4 & $245 / 604$ & 40,6 & $266 / 604$ & 44 \\
\hline Total & $\mathbf{1 5 9 / 1 3 4 1}$ & $\mathbf{1 1 , 9}$ & $\mathbf{4 8 5 / 1 3 4 1}$ & $\mathbf{3 6 , 2}$ & $\mathbf{6 9 7 / 1 3 4 1}$ & $\mathbf{5 2}$ \\
\hline
\end{tabular}

A Figura 04 demonstra que a distribuição do abaixamento entre os municípios, no que diz respeito às faixas etárias, é bastante heterogênea, alcançando frequência categórica em 07-Seringueiras e 14-Pimenta Bueno. Observa-se também que, dentre as microrregiões, o Vale Guaporé-Mamoré e o Cone Sul possuem frequência muito elevada de abaixamento, diferentemente da Região Norte que apresentou frequência mais equilibrada entre a primeira e a segunda faixa etária.

Figura 04. Abaixamento da vogal média anterior em posição pretônica (faixa etária)

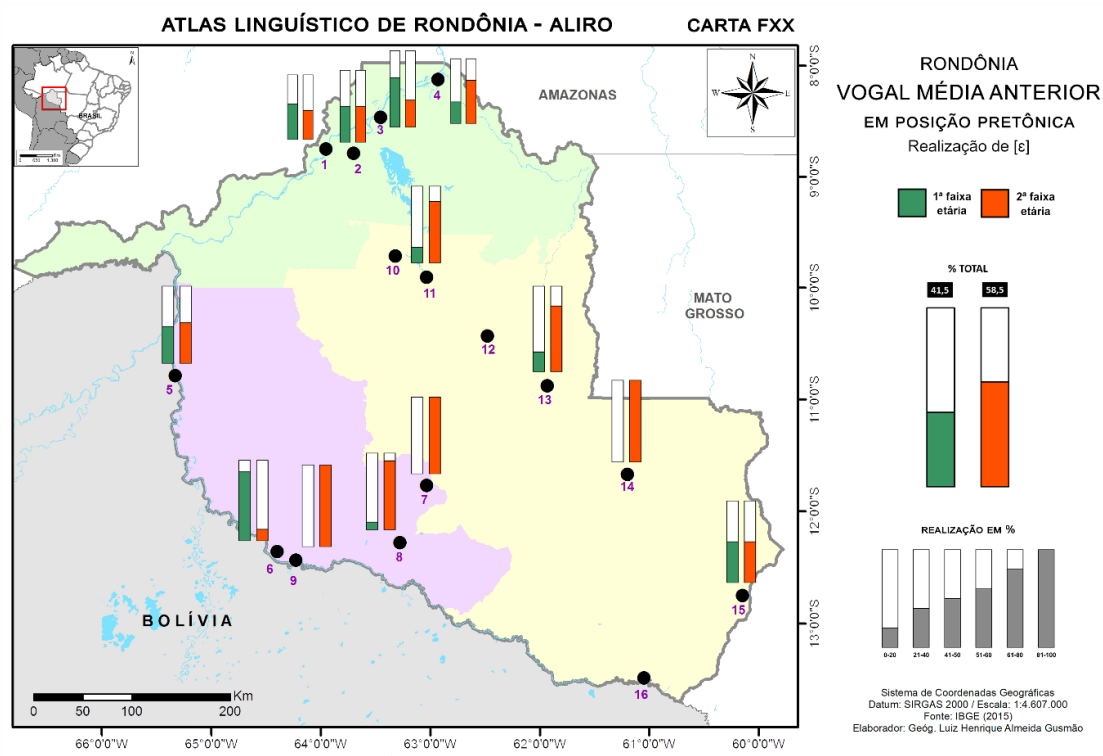




\subsection{Agrupamentos fonéticos}

As variantes levantadas neste estudo (abaixamento, alçamento e manutenção) foram presentes em todas as localidades, à exceção de 16-Pimenteiras, na qual não ocorreu abaixamento. No entanto, as variantes se concentraram em localidades específicas, formando configurações geográficas complexas, constituindo, portanto, um contínuo diferente para cada uma dessas variantes.

A Figura 05 demonstra a formação de três macroagrupamentos, no qual Ma1 constitui o agrupamento de manutenção de /e/ pretônico, obtendo, ao todo, $52 \%$ de frequência; Ma2 se refere ao agrupamento de alçamento de /e/ pretônico, o qual atingiu $36,2 \%$ de frequência; por fim, Ma3 concerne o agrupamento de abaixamento de /e/ pretônico, tendo frequência de $11,9 \%$ no total.

Figura 05. Macroagrupamentos fonéticos da vogal média anterior em posição pretônica
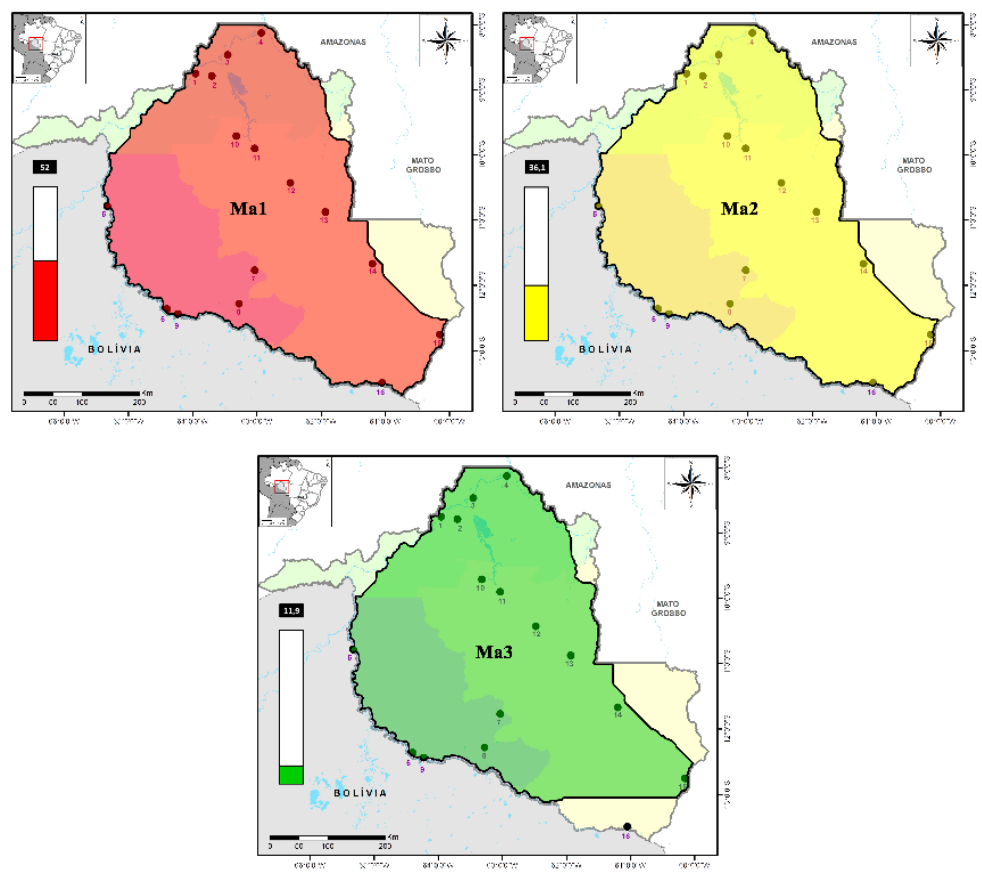
Figura 06. Nano e microagrupamentos fonéticos da vogal média anterior em posição pretônica

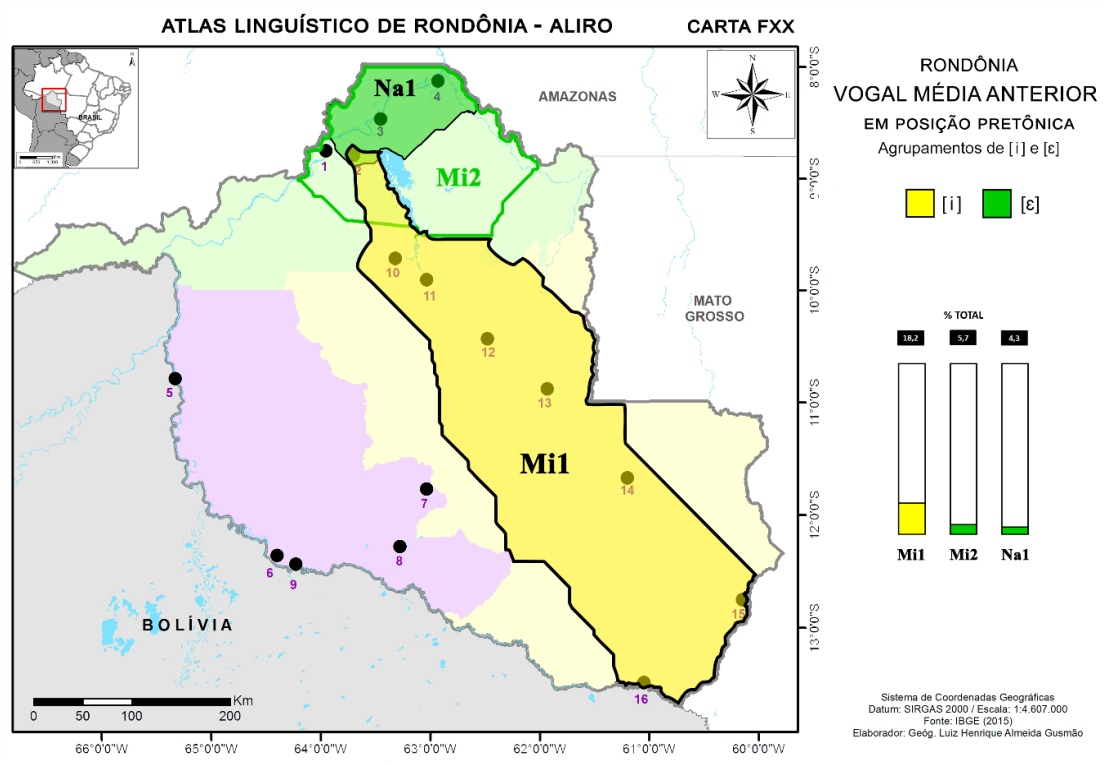

A Figura 06 demonstra que há uma grande concentração de alçamento de /e/ pretônico no território rondoniense. O alçamento dessa vogal obteve 18,2\% dentre as localidades em que essa variante foi mais frequente, as quais estão abarcadas em Mi1. Esse microagrupamento abrangeu toda a microrregião do Cone Sul e se estendeu para a Região Norte, contemplando a localidade 02-Candeias. O Mi2, por sua vez, compreende o microagrupamento de abaixamento da vogal /e/ pretônica, o qual foi registrado na Região Norte, obtendo frequência total de 5,7\%. Por fim, dentro do Mi2, há a formação do nanoagrupamento Na1, que abrange as localidades 02-Candeias, 03-São Carlos e 04-Calama, as quais atingiram, respectivamente, $18,2 \%, 19,5 \%$ e $27,6 \%$ de frequência, sendo essas as localidades que obtiveram os maiores percentuais de abaixamento de /e/.

Ressalta-se que, quando os agrupamentos são traçados em um território, não se rompe o contínuo variacional que há nas regiões destacadas. O agrupamento exerce a função de demonstrar que determinados espaços geográficos possuem maior tendência de realização de alguma variante do que os demais espaços.

\section{CONSIDERAÇÕES FINAIS}

Os resultados apresentados evidenciam que a vogal /e/ em posição pretônica apresenta um continuo variacional de abaixamento, alçamento e manutenção.

Os resultados concernentes aos fatores externos mostram que a variável diassexual não exerce influência significativa sobre a realização da variável dependente /e/ em posição pretônica. A variável diageracional, no entanto, indica 
uma tendência significativa de uso: o abaixamento da vogal /e/ pretônica obteve maior frequência na $2^{a}$ faixa etária, ao passo que a manutenção dessa vogal teve maior frequência na $1^{\mathrm{a}}$ faixa etária. Esse fator não foi pertinente na realização do alçamento, embora a $2^{\mathrm{a}}$ faixa etária tenha sido a que mais alçou a vogal /e/. Esse resultado pode levar a crer que há uma mudança em curso, visto que o abaixamento de /e/ se encontra majoritariamente na fala dos rondonienses mais velhos, enfraquecendo seu uso com o tempo.

O fator diatópico, por sua vez, apresenta influência sobre o uso da variável /e/, demonstrando que as dimensões de macroagrupamento, microagrupamento e nanoagrupamento são configurações geográficas complexas e pertinentes. Destaca-se, ainda, que a Região Norte apresenta sempre índices muito diferentes em relação às variantes de /e/, o que sugere uma investigação que verifique se o sul do estado de Amazonas não possui índices de abaixamento que se assemelham com os índices dessa variante na região Norte de Rondônia.

\section{REFERENCIAS}

ARAGÃO, M. S. S. As vogais pretônicas no falar nordestino: os dados do ALiB. In: VI Congresso Internacional da ABRALIN. VI Congresso Internacional da ABRALIN - Anais. João Pessoa, PB: Idéia- Editora, 2009, p. 2250-2258.

BESSA, J. Atlas Linguístico do Ceará. Vol. I-Introdução, Vol.II - Cartogramas. Universidade Federal do Ceará. Fortaleza: Edições UFC, 2010.

BISOL, L. Harmonização vocálica: uma regra variável. Rio de Janeiro, 1981. Tese (Doutorado) UFRJ.

BRANDÃO, S.; CRUZ, M. L. Um estudo contrastivo sobre as vogais médias pretônicas em falares do Amazonas e do Pará com base nos dados do ALAM e do ALiSPA. In: AGUILERA, V. (org.). $A$ geolinguística no Brasil: trilhas seguidas, caminhos a percorrer. Londrina: Eduel, 2005.

CALLOU, D.; LEITE, Y. As vogais pretônicas no falar carioca. Estudos Lingüisticos e Literários (5), Salvador: UFBA, 1986.

CÂMARA JR., J. M. Princípios de Lingüistica Geral: como introdução aos estudos superiores da língua portuguesa. $5^{\text {a }}$ ed. Rio de Janeiro: Padrão, 1977.

CARDOSO, S. Geolinguística: ampliando fronteiras para o conhecimento do português do Brasil. In: RAZKY, A.; OLIVEIRA, M.; LIMA; A. (orgs.). Estudos Geossociolinguísticos do Português Brasileiro. Campinas: Pontes Editores, 2017, p. 119-136.

COMITÊ NACIONAL DO PROJETO ALiB. Atlas Linguístico do Brasil: Questionários. Londrina: Ed. UEL, 2001.

CRUZ, M. L. Atlas Linguístico do Amazonas (ALAM). 2004. Tese (Doutorado em Letras Vernáculas) - Faculdade de Letras, UFRJ, Rio de Janeiro, 2004. 
DIAS, M. As vogais médias pretônicas nas capitais da região Norte do Brasil. Pará, 2012. Dissertação (Mestrado) - UFPA.

GUY, G.; ZILLER, A. Sociolingüistica Quantitativa: instrumental de análise. São Paulo: Parábola Editorial, 2007.

ISQUERDO, A.; ROMANO, V. Discutindo a dimensão Sociolinguística do Projeto ALiB: uma reflexão a partir do perfil dos informantes. Alfa, São Paulo, v. 56, p. 891-916, 2012.

MOTA, J. A.; CARDOSO, S. A. M. Sobre a Dialetologia no Brasil. In.: MOTA, J. A.; CARDOSO, S. A. M. Documentos 2: Projeto Atlas Linguístico do Brasil. Salvador: Quarteto, 2006, p. 15-34.

NASCENTES, A. O linguajar carioca. Rio de Janeiro: Organizações Simões, 1953

OLIVEIRA, D. ALMS - Atlas Lingüístico de Mato Grosso do Sul. 1. ed. Campo Grande: Editora UFMS, 2007, p. 271.

RADTKE, E; THUN, H. Nuevos caminos de la geolinguística románica. Un balance. In: RADTKE, E.; THUN, H. Neue Wege der Romanischen Geolinguistik. Kiel: Westensee-Verlag, 1996. p. 25-49.

RAZKY, A. (org.). Atlas linguístico sonoro do Pará. Belém: PA/CAPES/UTM, 2004. [CD-ROM]

RAZKY, A. A dimensão sociodialetal do léxico no projeto Atlas Linguístico do Brasil. SIGNUM: Estud. Ling., Londrina, n. 16/2, p. 247-270, dez. 2013.

RAZKY, A. et. al. Atlas Linguístico do Amapá. São Paulo: Labrador, 2017.

RAZKY, A. O Atlas Geo-sociolinguístico do Pará: abordagem metodológica. In: AGUILERA, Vanderci Andrade (orgs.). A Geolinguística no Brasil: caminhos e perspectivas. Londrina: EDUEL, 1998, p. $155-164$.

RAZKY, A. Uma perspectiva geo-sociolinguística para a análise do status da variável /s/ em contexto pós-vocálico no nordeste do estado do Pará. Dans Estudos Linguísticos e Literários. n. 41, Salvador, Programme de Pos-graduação en Langue et Culture, UFBA, 2010.

RAZKY, A.; LIMA, A.; OLIVEIRA, M. As vogais médias pretônicas no falar paraense. SIGNUM: Estud. Ling., Londrina, n. 15/1, p. 293-310, jun. 2012.

RAZKY, A.; GUEDES, R. Le continuum des regroupements lexicaux dans l'Atlas Geossociolinguístico do Pará (ALiPA). In: CONTINI Michel e LAI Jean-Pierre. La géographie linguistique au Brésil. Geolinguistique. Grenoble: ELLUG, 2015, p.149-162.

RAZKY, A.; SANCHES, R. D. Variação geossocial do item lexical 'riacho/córrego' nas capitais brasileiras. GRAGOATÁ, v.21, n.40, p.70 - 89, 2016

RAZKY, A.; COIMBRA, D.; COSTA, E. O. Variação léxico-semântica e agrupamento lexical do item cambalhota no Atlas Léxico Sonoro do Pará (ALeSPA). Lingua e Instrumentos Linguísticos, v.40, p. 151-169, 2017.

ROMANO, V. P.; SEABRA, R. D.; OLIVEIRA, N. SGVCLin: Software para geração e visualização de cartas linguísticas. Revista de Estudos da Linguagem, v. 22, n.1, p.119-151, 2014. 
SANKOFF, D.; TAGLIAMONTE, S.; SMITH, E. Goldvarb X: A variable rule application for Macintosh and Windows. Department of Linguistics, University of Toronto, 2005.

SILVA NETO, S. Introdução ao estudo da língua portuguesa no Brasil. 2. ed. Rio de Janeiro: Instituto Nacional do Livro, Ministério da Educação e da Cultura, 1963[1950].

SILVA, A. No rastro dos pioneiros: um pouco da história rondoniana. Porto Velho: SEDUC, 1984.

Recebido: $15 / 01 / 2019$

Aceito: 11/02/2019

Publicado: 3/04/2019 